\title{
For "Translation and Theories"
}

\author{
Lili Ni \\ Department of Culture and Education \\ HLJ Province School of Administration \\ Harbin 150080, China \\ E-mail:cator-1982@sohu.com
}

\begin{abstract}
Translation studies stem from comparative literature and contrastive analysis. It involves the transfer of messages between two different language systems and cultures, and Munday (2001,p.1) notes that translation 'by its nature' 'is multilingual and also interdisciplinary'. Translation subjects are the texts in various publishing forms for different levels of reader; moreover, the language systems, linguistics, communications studies and cultural studies are also involved in research subjects, which all contribute to the difficulties of translation fulfilment.
\end{abstract}

Keywords: Translation, Theories, Structure, Expression

\section{New translation category}

Vinay and Darbelnet carried out a comparative stylistic analysis to describe translation shifts thought the term 'shift' was first used by John Catford in his A linguistic Theory of Translation (1965). This model is developed from taxonomies by proposing detailed lists of the categories for describing small linguistic changes in a specific translation pair.

Translation shifts $=$ small linguistic changes occurring in translation of ST to TT (Munday,2001,p.55)

The categorization of translation procedures given by Vinay and Darbelnet is very comprehensive. There are two main translation strategies, direct and oblique translation, covering all together seven concrete procedures. Direct and oblique translation in some degree are correspondent to literal and free translation respectively, one of the difference for their theory from the theories in 'pre-linguistics period' (Newmark,1981,p.4 ) is that Vinay and Darbelnet use detailed categories to substitute for macro-level's literal and free.

\section{Direct translation}

\subsection{Borrowing (Vinay and Darbelnet,2004,p.129)}

The SL word is transferred directly to the TL (Munday,2001,p.56).

eg. Sandwiches - sanmingzhi

Clinton-kelindun

Chinese characters is completely different from English letters, though direct transfer of the SL word is impractical, the SL will normally be changed into fixed Chinese characters with similar pronunciation. The application of this strategy is also a common way to bring new culture factors into native combination.

eg. shaping - shaping (the exercise for helping women to keep beautiful figures);

party - party; Lancôme-Lancôme

This is a new rising situation in translation studies, due to the development of education in country of target culture and the economic globalization as the prerequisite. For keeping the unanimous genre in some kinds of texts, translator should adopt this "original translation" method to translate words for the achievement of textual equivalence rather than translate these words into TL. Considering the skopos in a translation or in the action of translating, for a functionally adequate result, translator adopts 'absolute foreignization' to retain the exotic sociocultural style in the TT is reasonable.

The advantage of borrowing strategy is that it brings an original connotation to the word in TL. Chinese language create a new word by means of pronunciation, nevertheless, this method avoids misunderstanding to use other words without full equivalence in Chinese. As the spread and the acceptance of this new word, its signifier in Chinese form will at last acquire the original concept of SL, which is just like the creation of this word in signifier of SL form in the country of source culture. 


\subsection{Calque (Vinay and Darbelnet,2004,p.129)}

It is a strategy to 'borrow' the SL expression or structure and then transfer it in a literal translation.

eg. Science-fiction - kehuan [lit. 'science fiction']; White-collar - bailing [lit. 'white collar']

Calque is 'a special kind of borrowing', so, as borrowing strategy mentioned above, it has the same influence on the enhancement of cultural integration. However, sometimes this translation strategy will cause difficulties in conveying messages in the TL. A translation phrase jijiedewenhou[lit. 'Compliments of the Season'] can be found on the greeting card of China, which is from French calque Compliments de la Saison. Because of the culture gaps between China and France, Chinese people will be confused by odd translation. Why the greeting is for the reason of season? Hardly can people of target culture understand the relationship between 'season' and greeting. Considering to the aspect of pragmatics, this strategy fails to achieve the equivalent response in the TT.

Pragmatics is the study of language in use. It is the study of meaning, not as generated by the linguistics system but as conveyed and manipulated by participants in a communicative situation.

(Baker,1992,p.217)

The transfer of the expression of SL in literal way brings about gaps between the coherence and presupposition in pragmatics. Coherence refers to 'receiver's expectations and experience of the world' (p.219). Presupposition refers to 'the knowledge the sender assumes the receiver to have or which is necessary in order to retrieve the sender's message' (Munday,2001,p.98). If the information within the boundary of coherence exceeds that of presupposition, the target reader can not get the message in the TT, though this strategy is applied by using literal translation word by word. The first time when the word qijiandian [lit. 'flag warship shop'] came out on an advertisement in China, I wondered it was so strange for a shop to sell ship flags in city centre. Until recently I found the phrase flagship Harrods (the main department store of Harrods chains in London), I had not realized that qijiandian was a odd translation from English, which means the most important shop among the chains. Before using the calque strategy, translator should make sure that the coherence of translation has pragmatical effects in target culture, or translation will fail to deliver the message of ST.

One of the advantages of calque strategy is the application to implicature, another concept of pragmatics, which is defined by Baker (1992,p.223) as 'what the speaker means or implies rather than what s/he says'. The meanings of the implications in the ST may cause difficulties for the translator, because the author of the TT is liable to give his real meanings for a special intension by using patterns which seems to be irrelevant. If the translator transfers the expression form of ST into another form in the TT, this translation faces the possibility of register change. Hence, keeping the original expression form in literal translation is relatively a safe way.

\subsection{Literal translation (Vinay and Darbelnet,2004,p.130)}

A 'word-for-word' translation. It is a translation strategy used 'most common between languages of the same family and culture'.

Chinese is a language transferring message by parataxis while English and most other modern languages in the world are in the nature of hypotaxis. The expression forms of the language of parataxis are very loose, and in most situations the arrangement for the segments of language are arbitrary. Such kind of language as Chinese is developed from the traditional expression patterns involving complex combinations of morpheme or phrase units, and it can be also arranged in written form by writer's train of thought to complete the whole sentence. In contrast, English demand formal principles to lead sentences, which can be called 'grammar' for the language of hypotaxis. As to Chinese, there are only what can be called basic rules to linguistic patterns instead of comprehensive grammar studies in English and French.

Kernel sentence described in Chomsky's generative-transformational model, which is a universal feature of human language, is the most basic part in language structure. 'Literal transfer' (Nida and Taber,1969,p.39) is the first one of the three stages for transferring message in the TL from kernel level to surface level. Although literal translation in English-Chinese translation is uncommon as a result of the dramatic differences for their language systems, it is still a preferable method for the translation of kernel sentences.

However, say Vinay and Darbelnet (1995,p.34) that literal method is 'unacceptable' in these occasions:

\subsection{1 it gives another meaning}

eg. The couple lead a cat and dog life. -Zhedui fuqi zongshi zhengchao.

[lit. 'The couple always quarrel.']

To convey the original message to the target text is the basic and main aim of translation. If translator explains this sentence in a literal way, the translation means in target culture that the couple is very poor and humble in a living condition like vagrant cats and dogs. Translation involves a process of decoding and encoding of language units. Before 
the second half of the twentieth century, translation topics focused on the debate over the word-for-word and sense-for-sense principles. The theories in that era neglect the practical effects for communication and the culture basis of the target text as well as the source text.

Nida (1964,p.159) developed these two terms as 'two basic orientations':formal equivalence and dynamic equivalence. Formal equivalence is concerned that 'the message in the TL should match as closely as possible the different elements in the SL', which is closely oriented towards the ST structure. Dynamic equivalence takes 'the principle of equivalent effect as its basis. When formal and dynamic equivalence are incompatible in translation, dynamic equivalence should be taken into first consideration because it gives 'the closest natural equivalent to the SL message'. Although there is no an objective standard yet to measure the equivalent effect, at least Nida's theory takes culture expectation into consideration. 'The closest natural equivalent to the SL message' is the goal of dynamic equivalence. Hence, the TT 'lead a cat and dog life' should be translated in SL as the meaning of 'quarrel'.

\subsection{2 has no meaning}

eg. The storage time is made small. - Chucun qixian biande henduan .

[lit. 'The storage time is made short.']

eg. couch potato - dianshiyinjunzi [lit. 'TV-addict']

In Chinese the word xiao[lit. 'small'] can only be used to describe the volume and dimension, while in English this word can also be used to describe time span instead of 'short'. The language patterns are different from country to country; literal translation thus makes the translation illegible to target readers. When there is rhetoric in translation, literal translation usually fails to give target reader the information of the ST. The way to translate metonymy and metaphor is different from the way to translate simile. Because simile contain such words as 'like', 'as' and 'as if', the target readers can receive them as symbols of rhetoric. However, in some texts by translating metonymy and metaphor in a literal way the TT is incomprehensive for the dramatic shifts of meaning, eg. 'couch potato'.

\subsection{3 is structurally impossible}

eg. Chunshui biyu tian [pronunciation:tian],Huachuan tingyu mian [pronunciation:mian]-

The spring water is bluer than the unclouded sky,

In a painted barge listening to the rain I lie.

Literal translation is unsuitable to be used for literary works, especially for the translation of poetry, which is the field emphasizing usually the creation of a new independent poem. Poems convey authors' expression by individual style and pronunciation in a certain form. Both lexically and grammatically, the information given in TT by literal translation is what can be called the explanation of the poem but not a work in literary style in target culture. Translation is more a process of explanation, interpretation and reformulation of ideas than a transformation of words. Newmark (1988,p.72) points out in the filed of the translation of poetry 'a translation can be inaccurate, [but] it can never be too literal'. The most important reason for translator abandoning of literal means is to keep the genre of the work.

2.3.4 does not have a corresponding expression within the metalinguistic experience of the TL

eg. hulu (A traditional paper-made decoration hung outside the door in Tomb-Sweeping Day of China)

The difficulties of literal translation are sometimes caused by linguistic or referential context. Translator could hardly find a correspondent word in TL because the words in any certain language are initiatively created as its cultural tradition or experience. In this case translator may as well to create a new word in TL according the rules of pronunciation and give an explanation for this word.

\subsection{5 has a corresponding expression, but not within the same register}

eg. jiaozi:Traditional food in Spring Festival of China, made of flour or starch with vegetable or meat stuffing, and it has standard shape designed by fingers.

Dumplings:1.Small ball of dough steamed or boiled. 2. Baked pudding made of dough filled with fruit.

Register covers a variety of elements according to House's model (1997,p.108). There are three variables in the first category of the model:field, tenor and mode. The social action is one of the references in the categories of field. Although these two subjects convey the similar linguistic message, dumplings lose the cultural information in register. In Jakobson's description, translation 'involves two equivalent messages in two different codes', however, he points out that 'there is ordinarily no full equivalence between code-units' (Jakobson,1959,p.114). From the view of linguistics, the relationship between the signifier (the spoken or written signal) and the signified (the concept signified) is formed by arbitrariness, and the divergence of the equivalence is objectively existed between the signifier of one language and the signified of another language. The achievement of the correspondence of word in field of contrastive linguistics is properly one reason for the translator to apply the word without equivalence in the TT. The word jiaozi is often 
translated into dumplings due to the similarities of the appearance of them, though they are in fact of no denotative equivalence. In order to avoid the ambiguity of translation, translator can either adopt pronunciation method and create a new word as jiaozi or translate jiaozi as Chinese dumplings.

\section{Oblique translation}

\subsection{Transposition (Vinay and Darbelnet,2004,p.132)}

The method involves 'replacing one word class with another without changing the meaning of the message'. eg. noun - adjective:The blockage was a success. - Fengsuo chenggongle. [lit. 'The blockage was successful.'] eg. preposition - verb:I found it by radar. - Wo liyong leida zhaodaole ta. [lit. 'I used radar, and then I found it.']

This strategy can also be found within a language, 'I give him a kiss' is semantically no difference from 'I kiss him' though the word 'kiss' is changed from a noun into a verb. According to Vinay and Darbelnet, the first expression can be called the base expression, while the converted form of 'kiss' as a verb is called the transposed expression. As a result of the divergence of language systems between SL and TT, this strategy to altering words without semantic change is undertaken probably most common and even sometime necessarily by translators. From a stylistic point of view these words are of different value in TL, and translators will face the possibility of changing the genre of the translation text. Baker (1992,p.167) compares nominalization and verbal forms in his 'thematic and information structures'. An inherent problem is that thematic structures meet different genre conventions in different language. The verb-inflected languages, such as Portuguese, Spanish and Arabic, often place the verb in 'theme' position. On account of the incompatibility to structure between different language systems, keeping balance of information dynamics related to textual function is still a dilemma in thematic structure. However, it is necessary that when adopting transposition the translator has the awareness to the 'relative markedness' of the words in the ST and pays attention to the meaningful choices made by the author.

3.2 Modulation (Vinay and Darbelnet,2004,p.133):refers to 'a variation of the form of the message, obtained by a change in the point of view'.

eg. God knows. - Meiren zhidao [lit. 'No one knows.']

eg. The length of $\mathrm{A}$ is three times less than that of B. $-\mathrm{B}$ de changdu shi $\mathrm{A}$ de sanbei. [lit. ' $\mathrm{B}$ is three times as long as A']

Modulation can be adopted when, though literal or transposition translation results grammatically correct utterance, the patterns of TL in the TT are considered as abnormal or awkward. The application of this skill demands very much the translator's capacity to mastering bilingual languages. Chinese is a very flexible language in pragmatics, and there are always several different expressions for the same idea, for example

Ta feichang yonggan. [lit. 'he is very brave'] and Ta sihao bu danqie [lit. 'he is not coward at all']. However, not all the word in English has a unique equivalent word in Chinese; both 'borrow' and 'lend' are translated as one Chinese word 'jie', thus modulation is ineffective for ambiguity when translating 'I borrowed him a book' and 'He lent me a book' in Chinese.

\subsection{Equivalence (Vinay and Darbelnet,2004,p.134)}

It refers to a strategy to describe the same situation by 'using completely different stylistic or structural methods' for producing 'equivalent texts'.

eg. spend money like water - huijin rutu [lit. 'spend money like earth']

eg. They are as different as chalk and cheese. - Tamen youzhe tianrang zhibie.

[lit. 'They are as different as sky and earth.']

eg. He was like a cat on hot bricks before the exam. - Kaoshi qian ta jide xiang reguoshang de mayi.

[lit. 'Before the exam he was like an ant on a hot pan.']

Equivalence is not only useful but also necessary in translating idioms and proverbs. This strategy is viewed as a type of modulation and 'a linguistic sub-discipline of pragmatics' (Armstrong,2005,p.152), which is concerned with the use of language in different cultures. For example, in Chinese 'east wind' means the wind in spring, while England is located in the west hemisphere, so that it must be changed into 'west wind' for foretelling that spring is coming. One country's history and culture affect the language used in this country very much. As the first example I made, there are two different words for describing extravagance, because English people live in islands while Chinese people live on the Asian continent, so the most common matter in their eyes are respectively water and earth. If translating these words and phrases simply in a literal way without any consideration to the idiom or proverb patterns in different cultures, the translator will give the TT ridiculous and even contrary information. 
The change in stylistics is another kind of application to equivalence. Language used in one style often has a contrary meaning against what seems to be its literal meaning. The basic function of the sentence 'Would you mind closing the window?' is a request for information; however, this general question in stylistics will be translated in Chinese as an imperative sentence 'Qing ba chuangzi guanshang' [lit. 'Close the window, please.'].

\subsection{Adaptation (Vinay and Darbelnet,2004,p.134)}

It refers to a method 'used in those cases where the type of situation being referred to by the SL message is unknown in the TL culture'.

eg. Lovely weather, isn’t it? -Chifan le ma? [lit. 'Have you finished your meal?']

Rather than operations on linguistic level, this strategy focus on phenomena or practices that are absent in the target culture. In a literal translation, Chinese people will be surprised why people always talk about weather like a meteorologist when they meet each other, while the English people will have the doubt whether the speaker has an intention to invite me for dinner. Although these expression patterns are irrelevant and strange to people from other cultures, both sentences in the example above can be translated as 'how do you do?', and by adopting this method an equivalence of the same value is created in both ST and TT.

\section{Application of Theory}

There are five steps given by Vinay and Darbelnet for moving from ST to TT (p. 30):

(1). Identify the units of translation.

(2). Examine the SL text, evaluating the descriptive, affective and intellectual content of the units.

(3). Reconstruct the metalinguistic context of the message.

(4). Evaluate the stylistic effects.

(5). Produce and revise the TT.

The unit of translation is a 'unit of thought' as well as a 'lexicological unit' but also. Vinay and Darbelnet (1995,p.21) define it as 'the smallest segment of the utterance whose signs are linked in such a way that they should not be translated individually'. Some problems can be found in practical translation with this model. Firstly, the boundaries between units may be multiple, and there are several ways to divide the units into small or longer segments of thought, thus in this occasion the units between the TT and the ST fail to be equivalent. Secondly, the aim of Vinay and Darbelnet's strategies is to describe the process of translation; however, their model in fact focuses on the translation product due to the basic and crucial step for identifying units, which are based on the taxonomy of linguistic approaches. Lastly, shifts themselves are on the micro-level of translation, there is an uncertainty concerns how to deal with the register of the text.

\section{Conclusion}

Translation study is a new-developing academic subject, and due to its complexity and variety, a universal theory was difficult to be found in the past fifty years. The complexity of realization of pragmatics even determines that the translation theories can only be evaluated as ever-imperfect standards. Toury $(1995, \mathrm{p} .84)$ warns against 'the totally negative kind of reasoning require by the search for shifts', and without the consideration of higher-level discourse or the effect the changes might have on the reader, Vinay and Darbelnet's model is mainly proposed for describing the changes that occur in a specific ST-TT pair, which highlight the liability to make error, failure and loss in translation. However, Vinay and Darbelnet's classic taxonomy remains the most comprehensive categorization of differences between a pairs of languages, and it still has profound influences on a wide range of new-developing translation theories.

\section{References}

'A methodology for translation', in Venuti, L. (ed.) (2004). 2nd The Translation Studies Reader. London and New York: Routledge, pp.128-137.

A Textbook of Translation. (1988). New York and London: Prentice Hall.

Armstrong, N. (2005). Translation, Linguistics, Culture: A French-English Handbook. Clevedon: Multilingual Matters.

Baker, M. (1992). In Other Words. A Coursebook on Translation. London: Routledge.

Catford, J. (1965). A Linguistic Theory of Translation. London: Oxford University Press.

Gentzler, E. (1993). Contemporary Translation Theories. London and New York: Routledge.

House, J. (1977). A Model for Translation Quality Assessment. Tübingen: Gunter Narr. 
Jakobson, R. (1959). 'On linguistic aspects of translation', in Venuti, L (ed.) (2000)1st The Translation Studies Reader. London and New York: Routledge, pp. 113-118.

Munday, J. (2001). Introducing Translation Studies. Theories and Applications. London: Routledge.

Newmark, P. (1981). Approaches to Translation. Oxford and New York: Pergamon.

Nida, E. A. (1964). Toward a Science of Translating. Leiden: E.J.Brill.

Nida, E. A. and C. Taber. (1969). The Theory and Practice of Translation. Leiden: E.J.Brill.

Toury, G. (1995). Descriptive Translation Studies-And Beyond. Amsterdam and Philadelphia, PA: John Benjamins.

Vinay, J.P. and Darbelnet. (1995). Stylistique comparée du francais et de l'anglais: Méthode de Traduction. Paris: Didier. Translated and edited by J.C. Sager and M.J. Hamel (1995) as Comparative Stylistics of French and English: A methodology for Translation. Amsterdam and Philadelphia, PA: John Benjamins. 